\title{
ANALYZING THE BASIC METEOROLOGICAL ASPECTS OF A PARTICULATE AIR POLLUTION EPISODE OVER THE INDUSTRIAL AREA OF NORTHWESTERN GREECE DURING THE NOVEMBER 2009
}

\author{
KARAGIANNIDIS A.F., 2, * \\ TRIANTAFYLLOU A.G. ${ }^{1}$ \\ KARACOSTAS T.S. ${ }^{2}$
}

\author{
${ }^{1}$ Laboratory of Atmospheric Pollution and Environmental \\ Physics, School of Technological Applications, \\ TEl of Western Macedonia, 50100 Kozani, Greece \\ ${ }^{2}$ Department of Meteorology and Climatology, \\ School of Geology, A.U.Th., Thessaloniki, Greece
}

Received: $27 / 11 / 12$

Accepted: $17 / 05 / 13$ *to whom all correspondence should be addressed: e-mail: thankar@live.com

\begin{abstract}
The complex terrain basin of Amyntaio - Ptolemais - Kozani in Western Macedonia of Greece is an area characterized by increased industrial activity and therefore it demands continuous and assiduous environmental monitoring. A prolonged particulate matter air pollution episode was recorded in the area during November 2009. Basic meteorological aspects are analyzed, during the episode period. Daily and hourly PM10 and PM2.5 concentration measurements were used along with surface and lower atmosphere hourly meteorological parameters from 13 measuring stations. The observational data were supported by data produced by the meteorological component of an air pollution model.

The overall analysis showed that the episode was primarily the result of the synoptic setting of the middle and lower troposphere. An Omega blocking pattern which gradually transformed to a highover-low pattern prevailed over central and southern Europe during the episode's period. The examination of the vertical wind field in the lower troposphere and appropriate stability indices, revealed a continuous absence of significant convection. The weak horizontal wind field near the surface and the reduced mixing height combined with the lack of synoptic forcing resulted in the trapping of the pollutants in the lower troposphere and the recording of increased airborne particulate matter concentrations. The radical change of the synoptic setting in the first days of December marked the end of the episode.
\end{abstract}

KEYWORDS: stability, particulate matter, Omega block, high-over-low.

\section{INTRODUCTION}

Western Macedonia in Greece and especially the complex terrain basin of Amyntaio - Ptolemais Kozani (BAPK), hosts a considerable number of Power Stations (PS) facilities along with lignite mines that feed these PSs. As a result, the air quality of the area is significantly affected due to the large amounts of airborne particulate matter (PM) emitted by those facilities (Triantafyllou 2003). The thorough and precise analysis of any possible relations between the meteorological conditions and the atmospheric pollution may help to successfully forecast extreme air pollution episodes, providing the necessary time and information to prepare for, or even avoid them.

Significant work has been carried out in the subject around the globe. McKendry (2000) investigated the meteorological parameters affecting the PM10 levels in the Lower Fraser Valley, British Columbia in Canada, while Rodríguez et al. (2002) examined the origin of high summer PM10 and TSP (Total Suspended Particles) concentrations at rural sites in Eastern Spain, concluding amongst others, that breeze circulations are partly responsible for these extreme events. The dependence of urban air pollutants on meteorology in the area of Cairo was analyzed by Elminir (2005). It was shown that wind and humidity affected the concentration and speciation of the pollutants. Barbadimos et al. (2011) examined the possible influence of meteorology on PM10 trends and 
variability in Switzerland from 1991 to 2008 and indicated that wind and temperature are two of the most significant factors.

In Greece, many researchers have already addressed the problem. Kallos et al. (1993) studied a series of air pollution episodes in Athens during the period 1983-1990 concluding that "days with critical balance between synoptic and mesoscale circulations and/or days of warm advection in the lower troposphere" favor such episodes. Triantafyllou (2001) studied high PM10 concentration episodes in Eordea valley and showed that stagnant meteorological conditions are most frequently associated with these episodes. Flocas et al. (2009) concluded amongst others, that air pollution episodes in the Thessaloniki area are primarily associated with anticyclonic conditions, small temperature rise and sea breeze circulation. Larissi et al. (2010), studied the temporal and spatial distribution of the Air Quality Index (AQI) within greater Athens area (GAA) and showed that the higher values of the index (high AQI values are generally associated to high concentrations of specific pollutants) during the warm period of the year, are strongly associated with sea breeze. This association was also noted by Proias et al. (2012) in the Greek city of Volos.

The meteorological setting of a particulate air pollution episode during November 2009 is investigated in the present paper. The episode is identified by means of particulate matter concentration values in specific sites along the BAPK axis. The data used are: a) mean daily PM10 and PM2.5 concentrations from the atmospheric pollution stations network of the Greek Public Power Corporation (PPC) and the Laboratory of Atmospheric Pollution and Environmental Physics of the School of Technological Applications of TEI of Western Macedonia, b) operational ECMWF analyses data, c) soundings data and d) vertical profiles of the basic meteorological parameters, produced by a prognostic local scale meteorological model.

\section{THE AREA}

The BAPK is situated in a mountainous area of western Macedonia, Greece. It presents a NW to SE orientation, with Amyntaio at the north and Kozani at the south end. Figure 1 depicts a topographic map of the area, the 13 measuring stations (1. Kato Komi, 2. Petrana, 3. Kozani, 4. Koilada, 5. Oikismos B, 6. Pontokomi, 7. Mavropigi, 8. Oikismos A, 9. Pentavrisos, 10. Anargiroi, 11. Amyntaio, 12. Vevi, 13. Florina) and the 6 power plants sites (PS1. Agios Dimitrios, PS2. Kardia, PS3. Ptolemaida, PS4. Amyntaio, PS5. Meliti, PS6. Bitola).

\section{DATA AND METHODOLOGY}

Hourly observational data from stations belonging to the Greek Public Power Corporation (PPC) and to the Laboratory of Atmospheric Pollution and Environmental Physics of the School of Technological Applications of TEI of Western Macedonia are one of the primary data sets used. These data include surface wind speed and direction and PM10 and PM2.5 concentration measurements, extending from 1/11/2009 to $30 / 12 / 2009$. Based on the hourly observations, mean daily values are also computed. Daily PM10 values for November and December from 2006 to 2009 have also been used. Operational ECMWF analysis data of horizontal resolution of $0.25 \times 0.25$ degrees and temporal resolution of 6 hours, at all the basic pressure levels, are used to produce the required synoptic charts by means of Grid Analysis and Display System (GrADS). The Mean Sea Level Pressure (MSLP) and the $500 \mathrm{hPa}$ geopotential height fields are examined to define the synoptic conditions of the episode. The vertical wind velocity at the $700 \mathrm{hPa}$ level is used to identify possible synoptic forcing in the area.

The meteorological component of The Air Pollution Model (TAPM) is also used to produce hourly vertical profiles of specific atmospheric parameters like temperature, potential temperature, wind speed and direction and other useful variables like the mixing height for selected sites of the area. The Air Pollution Model (TAPM) is a PC-based, nestable, prognostic meteorological and air pollution model driven by a Graphical User Interface (GUI). The GUI allows the user to configure inputs, run the model and analyze outputs generated by the model. It is linked to databases of terrain height, land use, and sea surface temperature information. Data sets of synoptic scale meteorology inputs needed for simulation accompany the model. More details on TAPM equations and parameterizations, including the numerical methods used to solve the model equations, can be found in Hurley (1997), Hurley (2002a), Hurley et al. (2001), Hurley et al. (2005), while the model application in W. Macedonia region in Zoras et al. (2007) and Triantafyllou et al. (2011). The meteorological component of TAPM is an incompressible, non-hydrostatic, primitive equation model with a terrain - following vertical coordinate for three-dimentional simulations. It includes 
parameterizations for cloud micro-physical process, turbulence closure, vegetative canopy and soil, and radiative fluxes. The mean horizontal wind components $\mathrm{u}$ and $\mathrm{v}$ are determined from the momentum equations and the terrain following vertical velocity from the continuity equation. Potential virtual temperature $\theta_{\mathrm{v}}$ is determined from an equation combining conservation of heat and water vapor. Pressure is determined from the sum of hydrostatic and optional non-hydrostatic component. The boundary-layer height (Zmix) in convective conditions is defined as the first model level above the surface for which the updraft velocity decreases to zero, while in stable/neutral conditions it is defined as the first model level above the surface that has a vertical heat flux less than $5 \%$ of the surface value following Derbyshire (1990). More details about that can be found in Hurley (2008). Micro-physics is based on Katzfey and Ryan (1997) for warm rain, and include bulk parameterizations for condensation of water vapor, evaporation of cloud water and rain water, autoconversion and collection of cloud water to form rain water and an expression for the rainfall terminal velocity. The meteorological component of the model is nested within synoptic-scale analyses/forecasts that drive the model at the boundaries of the outer grid. The model is initialized at each grid point values of $\mathrm{u}_{\mathrm{s}}, \mathrm{v}_{\mathrm{s}}, \theta_{\mathrm{vs}}, \mathrm{q}_{\mathrm{s}}$ interpolated from the synoptic analyses. At the model top boundary, all variables are set at their synoptic values, while zero gradient boundary conditions are used for all variables at the lateral boundaries. The model run for a twenty days' period (15/11$5 / 12 / 2009$ ) using 25 vertical model levels, and three nested domains of $35 \times 35$ horizontal grid points at 30,10 and $3 \mathrm{Km}$ spacing for the meteorology. NCEP synoptic analyses were used at the outer grid boundaries. Pontokomi was considered as the center $(0,0,0)$.

Sounding data from the nearest sounding station (Thessaloniki) are used, mainly to determine the presence of vertical forcing through the examination of stability indices such as the Total Totals Index (TTI) (Miller, 1967), the Lifted Index (LI) (Galway, 1956; Blanchard, 1998), the K-Index (KI) (George, 1960) and the Showalter Index (SI) (Showalter, 1953). TTI values over 44 are associated with convective activity that increases as the index values increase. Values over 55 indicate very strong instability. LI values between -2 and -6 are indicative of convective potential while values below -6 are associated with very strong convection. SI values between 3 and -3 indicate possibility of showers and thunderstorms and values below -3 are indicative of very strong convective activity. Finally, KI values over 20 suggest possible convective activity, while values over 40 imply certainty of convection.

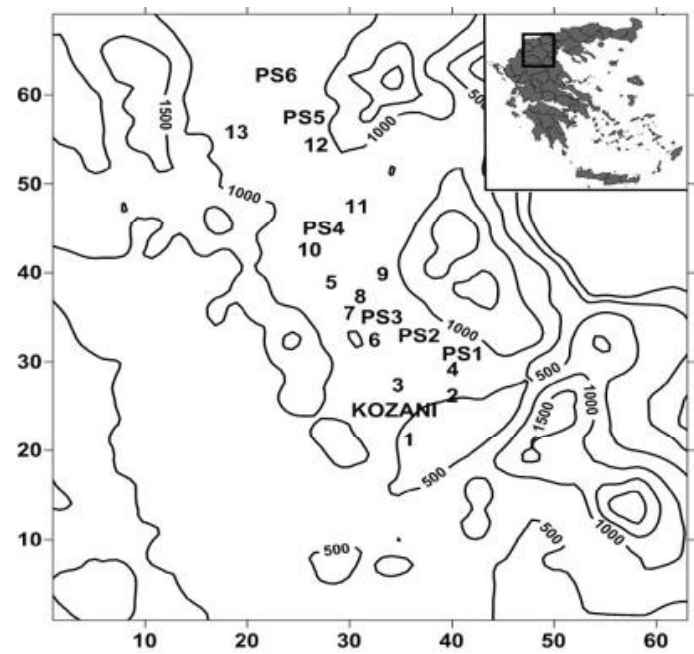

Figure 1. The study area. Measuring stations $(1,2,3, \ldots, 13)$ and power plants sites (PS1, PS2, .., PS6)

\section{RESULTS}

The definition of the exact time period of the episode is not a straightforward task, due to the diversity of the measuring sites. Daily PM10 mean values from November of 2006 to November of 2009 are used to calculate the November PM10 threshold daily value of the upper $25 \%$ of the distribution, for each measuring site. Any day with mean PM10 value exceeding this value is considered to be part of the episode. 


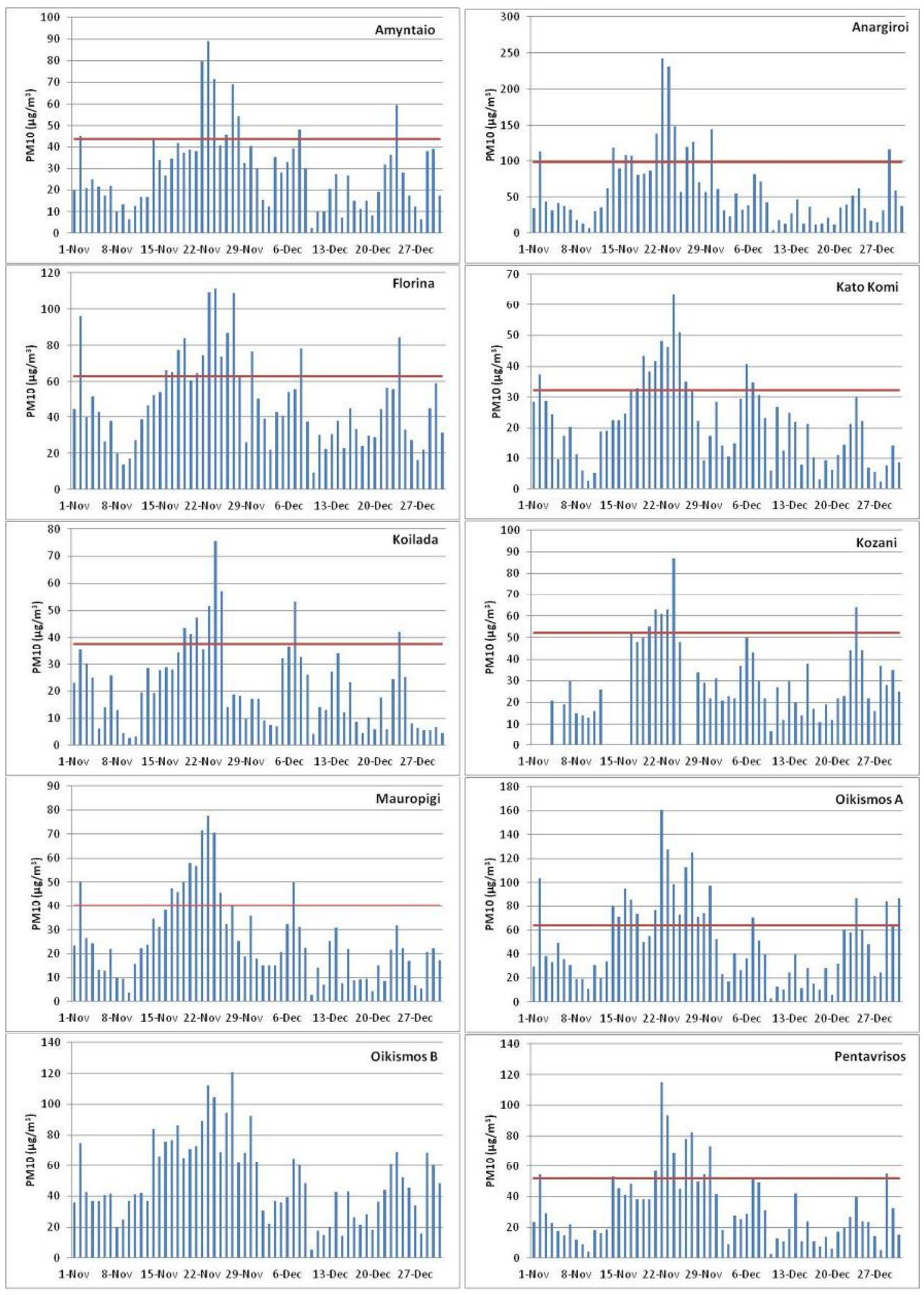

Figure 2. Daily PM10 concentration values, for all the available measuring stations. The red line indicates the PM10 threshold daily value of the upper $25 \%$ of the distribution 


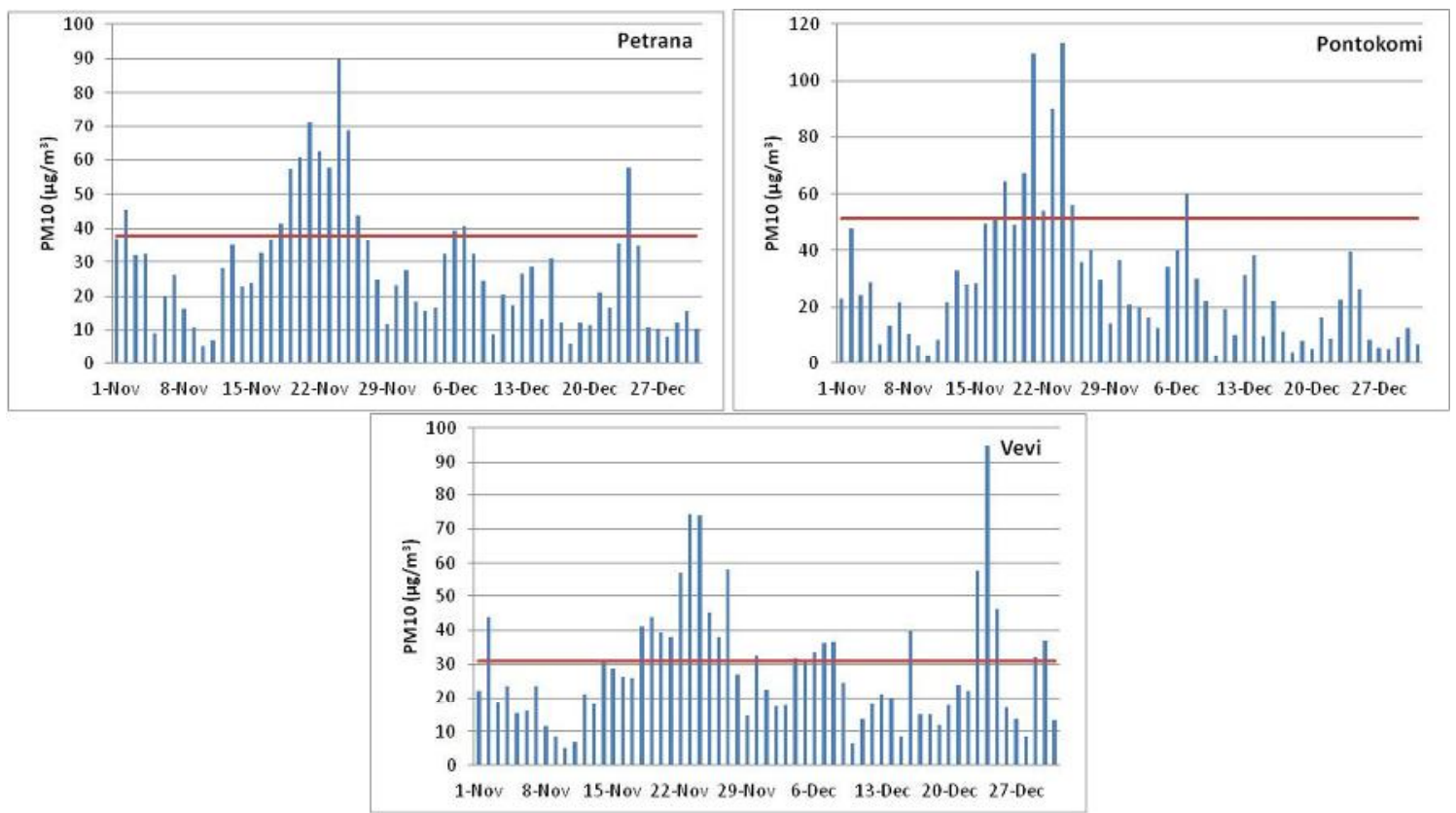

Figure 2 (continued). Daily PM10 concentration values, for all the available measuring stations. The red line indicates the PM10 threshold daily value of the upper $25 \%$ of the distribution

The studied episode starts at the $14^{\text {th }}$ of November for some of the stations and ends after the $25^{\text {th }}$, showing a peak between the $22^{\text {nd }}$ and the $24^{\text {th }}$ of November. The exact length depends on the measuring station. This is illustrated in Figure 2, where the time evolution of the daily average PM10 concentration for all the measuring sites is depicted. The threshold value of the upper $25 \%$ of the distribution is also shown as a continuous horizontal line (daily values for the station of Oikismos B for the period 2006-2009 were not available). In order to avoid falsely excluding part of the episode, it is considered to extend from the $14^{\text {th }}$ to the end of November of 2009.

The synoptic setting over the examined area is investigated based on MSLP and 500hPa synoptic charts. Southern Europe is dominated by an Omega block (Huschke 1959, Karacostas et al. 2006) from $17 / 11$ to $20 / 11$ as it can be seen in Figures $3 a$ and $3 b$. During the $21^{\text {st }}$ and $22^{\text {nd }}$ the Omega block gradually transforms to a high-over-low pattern (Figure 3c) that lasts until the night of the $23^{\text {rd }}$ of November. At the afternoon of the $24^{\text {th }}$ (Figure $3 \mathrm{~d}$ ) a short wave embedded on the almost stagnant long wave passes over Western Macedonia and reinforces temporarily the surface wind field. Another short wave passes over the area during the afternoon of the $28^{\text {th }}$ (Figure $3 \mathrm{e}$ ) causing light rainfall. A trough associated to a deep depression, approaches Greece during the $1^{\text {st }}$ of December (Figure $3 \mathrm{f}$ ) establishing a strong southeasterly flow and producing significant rainfall in western Macedonia during the $1^{\text {st }}$ and $2^{\text {nd }}$ of December. 

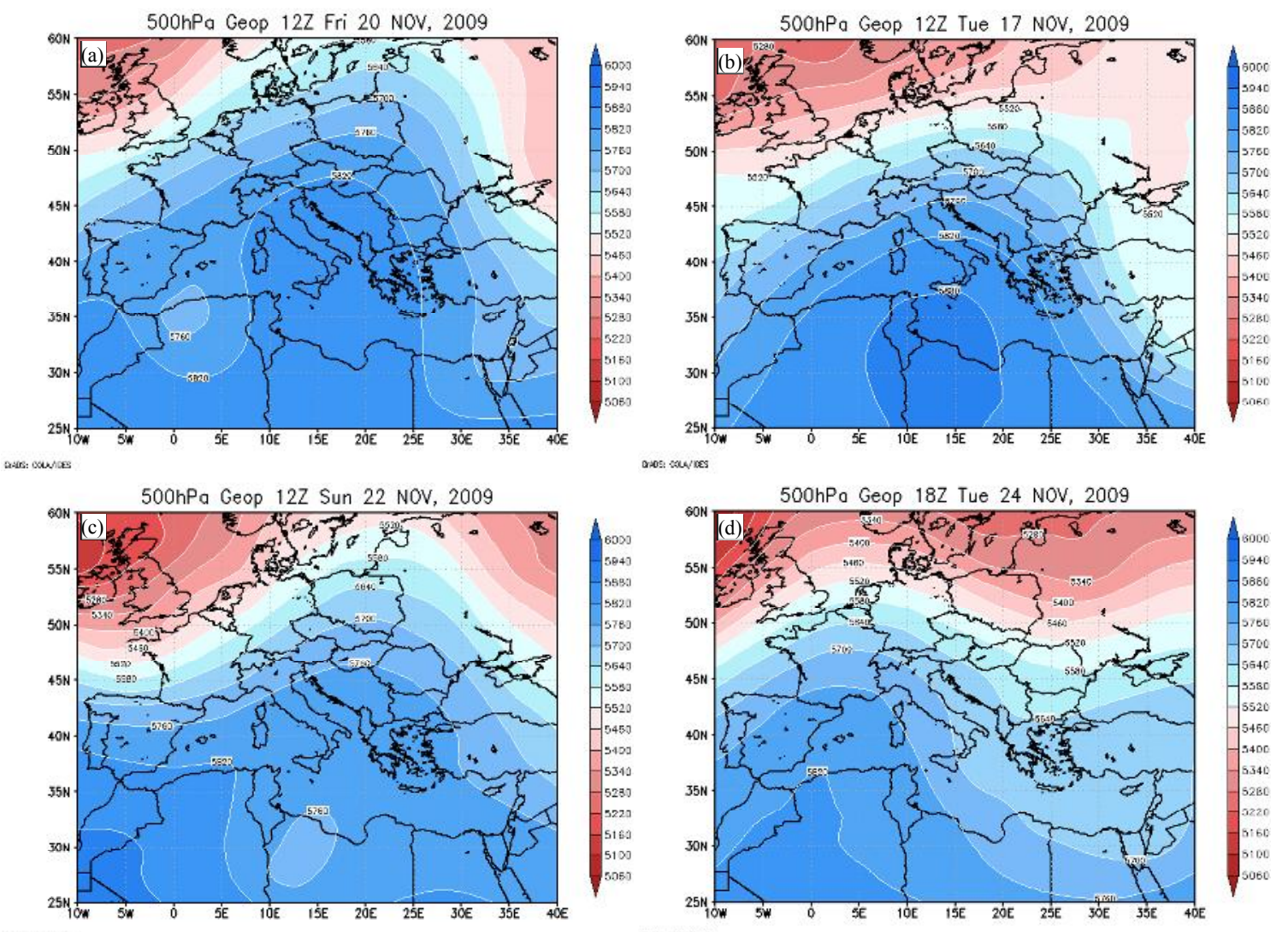
atas: caves
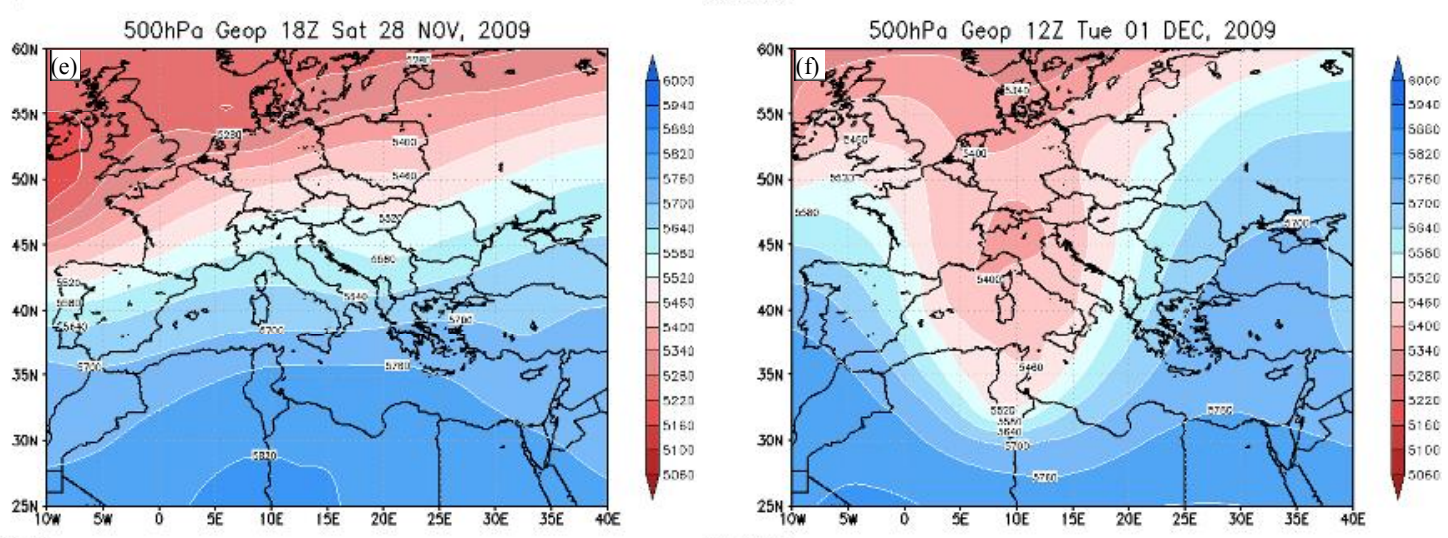

Figure 3. Geopotential height (in gpm) at the $500 \mathrm{hPa}$ level during significant time instances of the episode

Due to the Omega block that dominates the area, MSLP and therefore the associated surface wind field, is quite weak (Figure 4a), strengthening during the passing of the first short wave on the $25^{\text {th }}$ of November (Figure 4b). The horizontal wind field in the lower troposphere weakens again during the $26^{\text {th }}$ of November (Figure 4c) and strengthens again due to the second short wave of the $28^{\text {th }}$ (Figure $4 d$ ). The approach of the trough preserves the strong surface horizontal wind (Figure 4e) until the first days of December when the depression reaches the examined area (Figure $4 \mathrm{f}$ ). 

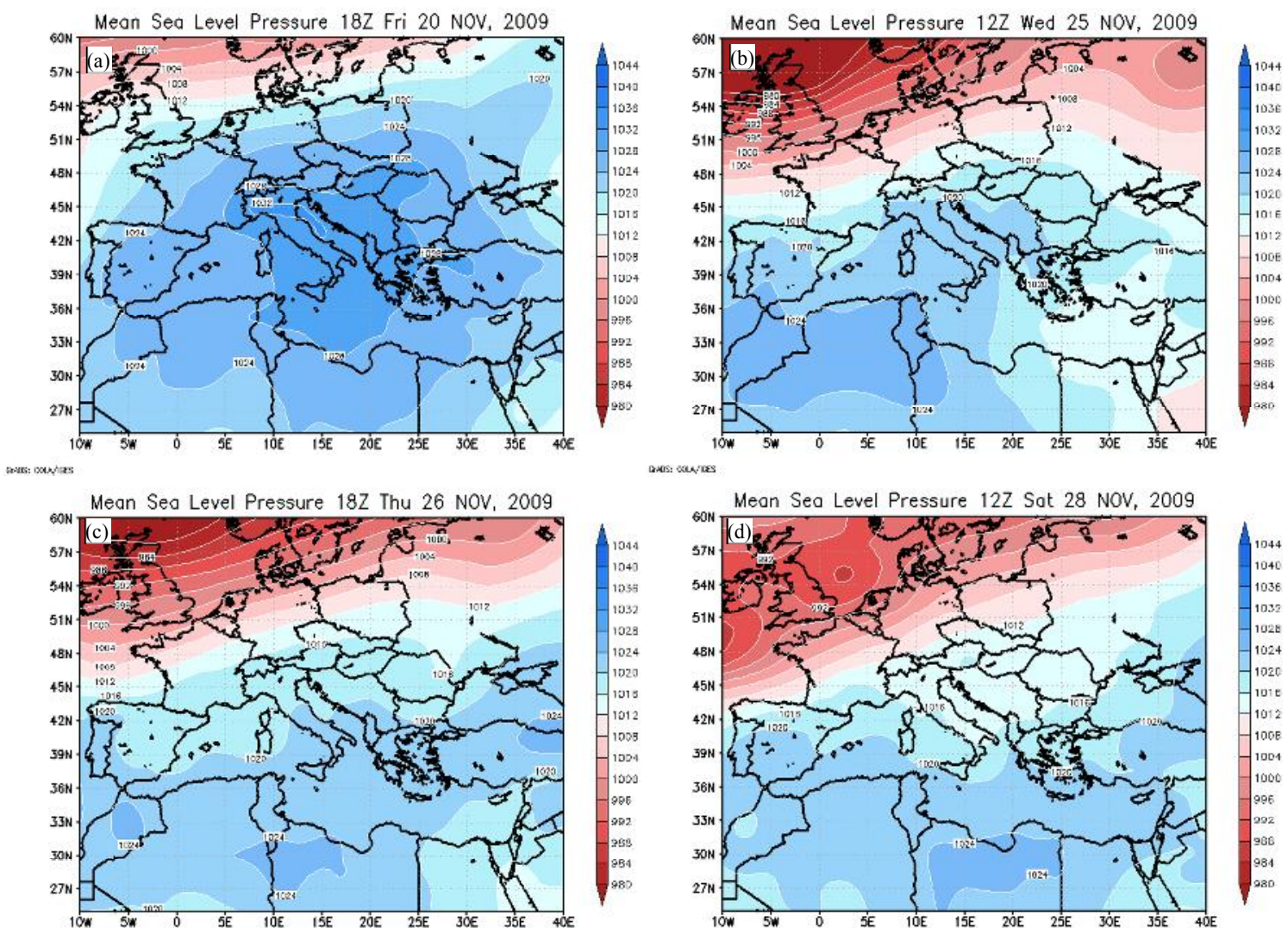
axis carines
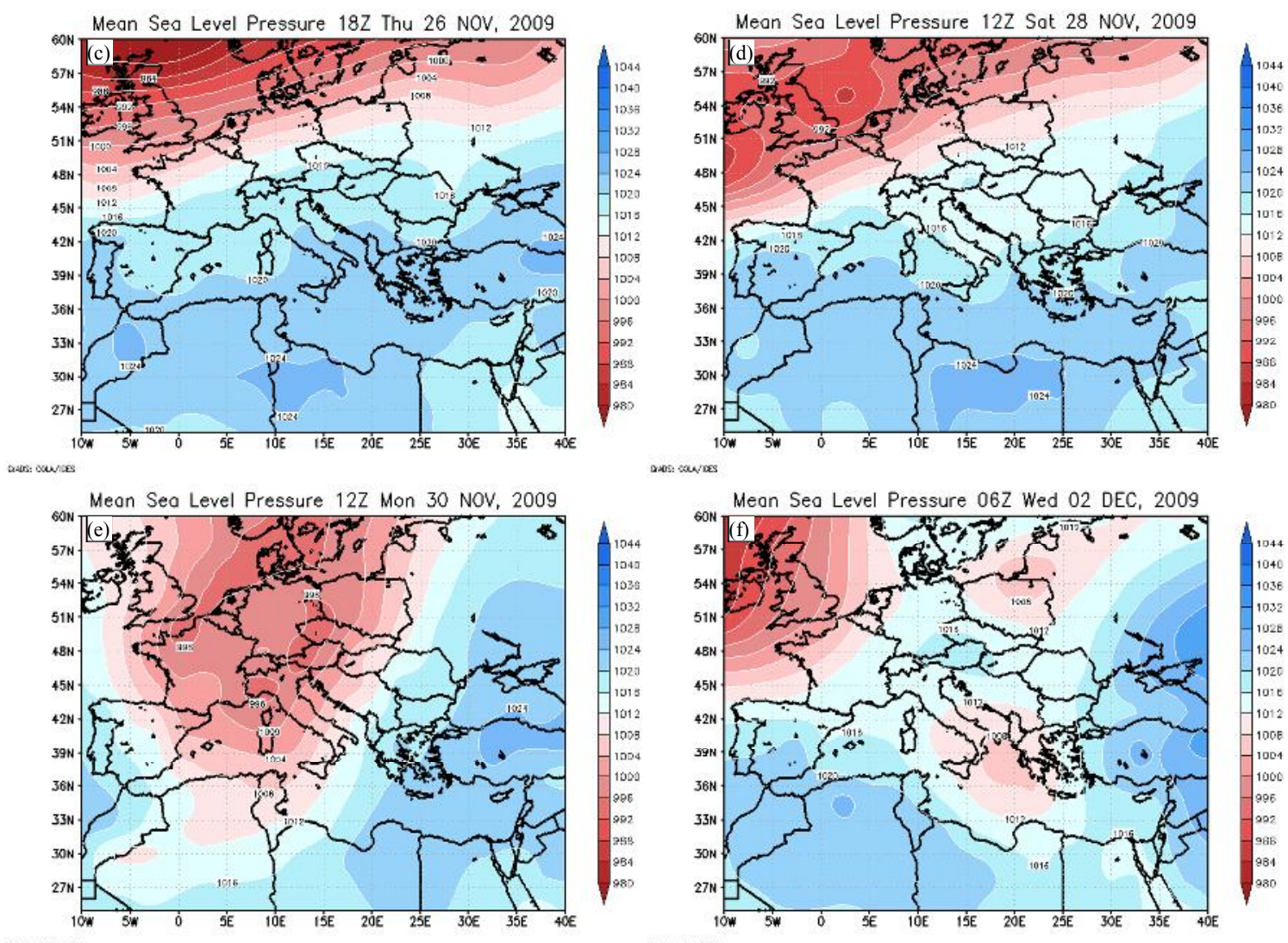

Figure 4. MSLP (in hPa) during significant time instances of the episode

The significant strengthening of the horizontal surface wind field, directly associated to the passing of the two shortwaves, is confirmed by the model's outputs, as can be seen in the Figure 5. During days of week synoptic surface pressure field like the $22^{\text {th }}$ of November (Figure $5 a$ and $5 b$ ), the horizontal surface wind is also very week and is formulated mainly by the local circulation patterns. The passing of the upper air shortwaves on the $25^{\text {th }}$ and the $28^{\text {th }}$ of November increases significantly the surface wind speed and homogenizes the surface wind direction (Figures $5 \mathrm{c}$ and $5 \mathrm{~d}$ respectively).

Lack of significant synoptic forcing during the days of the episode is revealed through the investigation of the omega vertical velocity in the pressure level of $700 \mathrm{hPa}$. As can be seen in Figure $6 a$ the area is dominated by week vertical motions that are usually less than $10 \mathrm{hPa} \mathrm{h} \mathrm{h}^{-1}$, even in the warm hours of the day. The passing of the first short wave during the afternoon of the $24^{\text {th }}$ does not change the situation significantly (Figure $6 \mathrm{~b}$ ), but the shortwave of the $28^{\text {th }}$ strengthens the vertical motions (Figure $6 \mathrm{c}$ ), resulting in light rainfall. The vertical wind field weakens again during the following hours (Figure 6d), until the arrival of the depression during the first days of December when increased vertical wind velocity is recorded in the area (Figure 6e). 


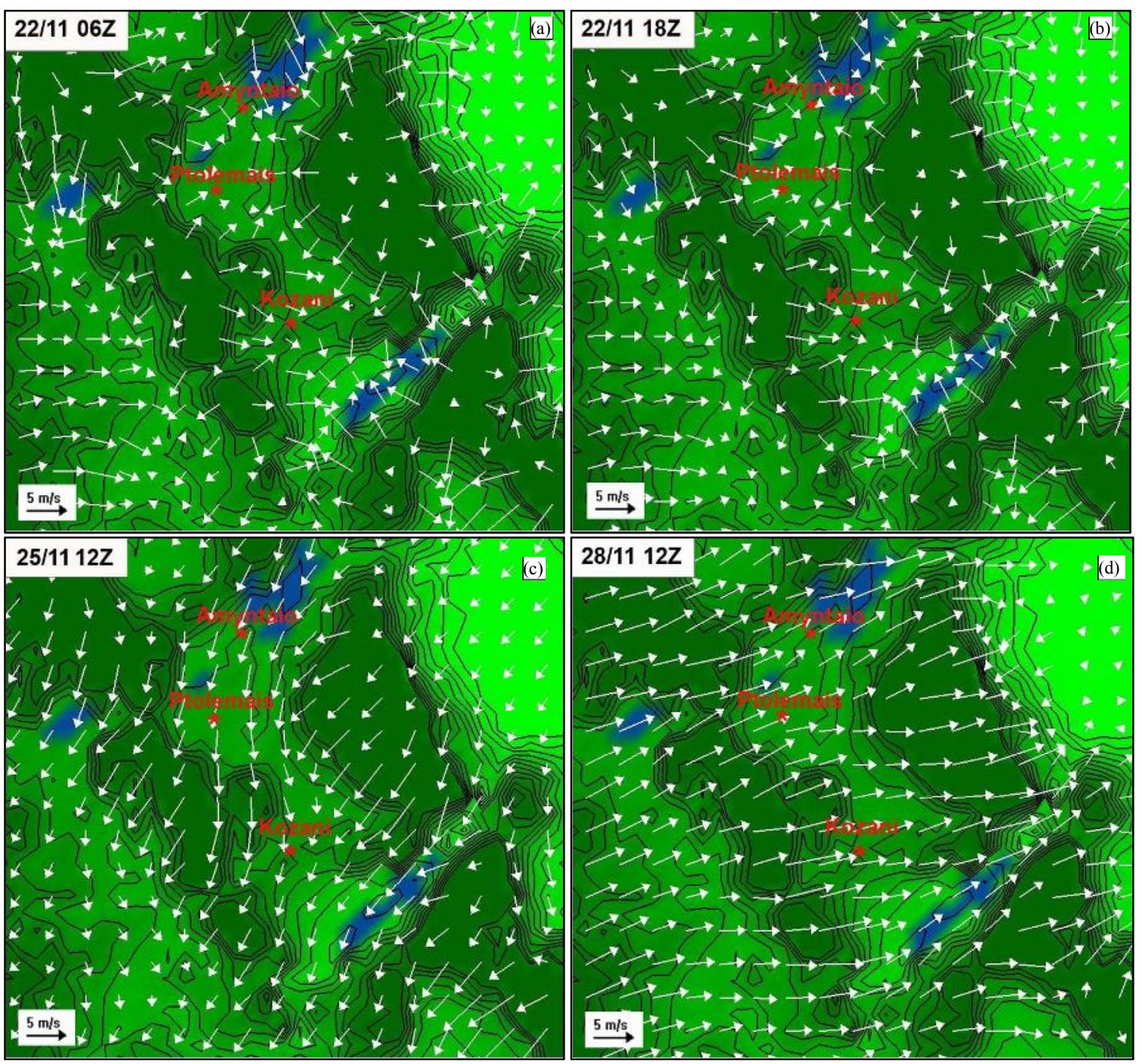

Figure 5. Surface wind field simulations during significant time instances of the episode
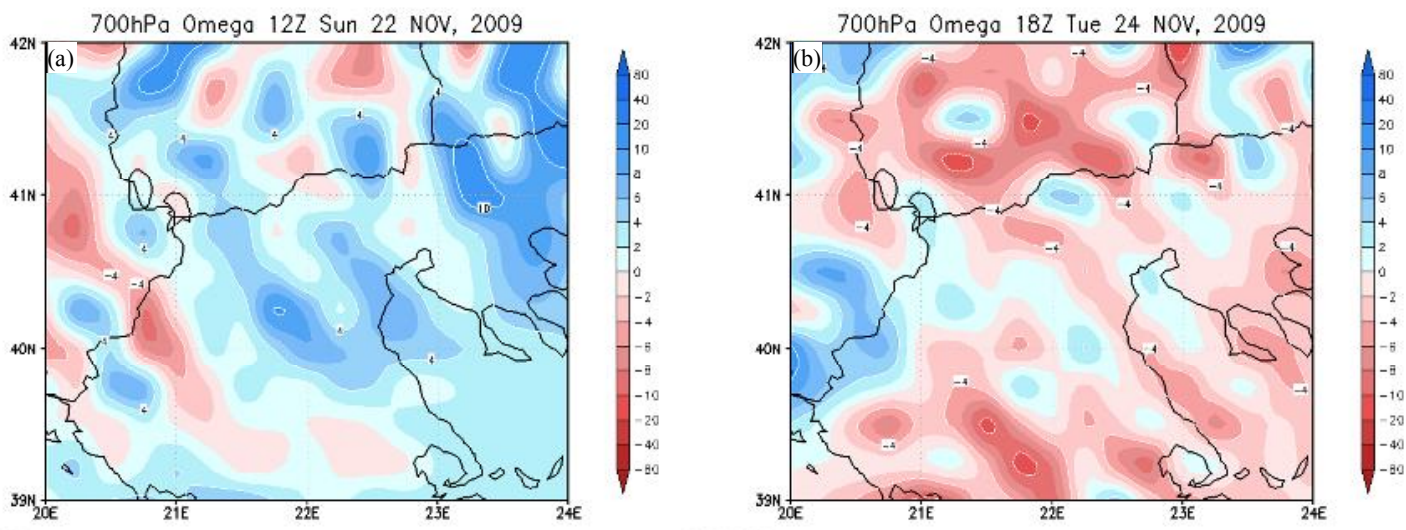

Figure 6. The vertical velocity field (in $\mathrm{hPa} \mathrm{h}^{-1}$ ) during significant time instances of the episode 

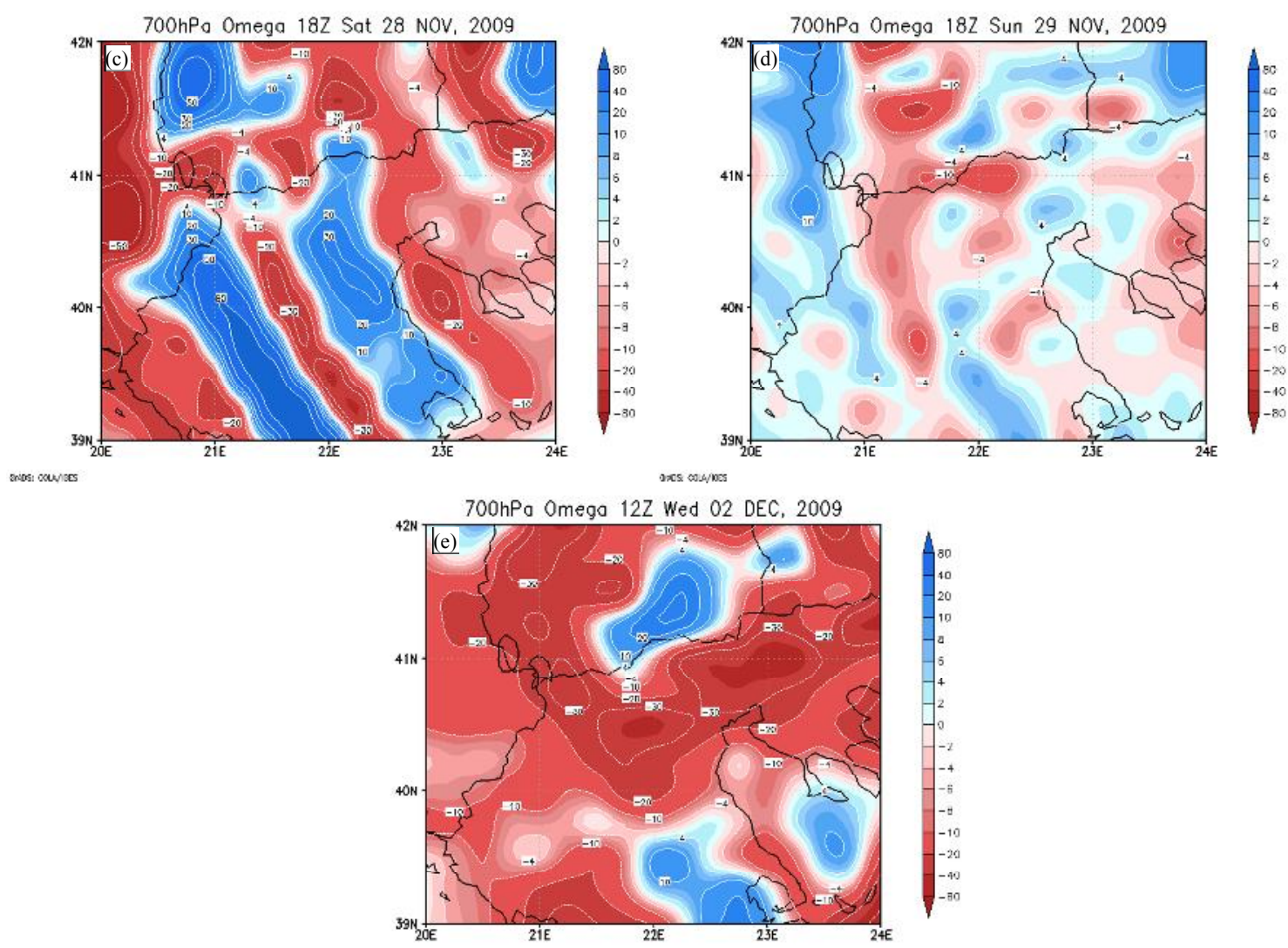

Figure 6 (continued). The vertical velocity field (in $\mathrm{hPa} \mathrm{h}^{-1}$ ) during significant time instances of the episode

An almost constant increase of PM10 and PM2.5 concentrations is recorded as the surface wind remains weak. During the $25^{\text {th }}$ of November when the wind field strengthens temporarily, PM10 values at Pentavrisos drop significantly. The same pattern appears after the $28^{\text {th }}$ of November when the wind field presents another significant increase (Figure 7a). An analogous decrease of PM2.5 concentrations values is recorded at Oikismos A, following the significant strengthening of surface wind after the $27^{\text {th }}$ of November (Figure $7 \mathrm{~b}$ ).

Hourly mixing height values are calculated by TAPM at various sites. Figure 8 shows the diurnal variation of this parameter from $15^{\text {th }}$ to $30^{\text {th }}$ of November at Pentavrisos and Oikismos A. Low mixing height values are recorded during most hours of the days, increasing only around midday. Moreover, a gradual decrease of the top of the mixing height until $22^{\text {nd }}$ of November is recorded. Another significant feature is the increased mixing height during the last hours of the $25^{\text {th }}$ and the first ones of the $26^{\text {th }}$ of November, that may be partially associated to the intensified vertical motions in the area.
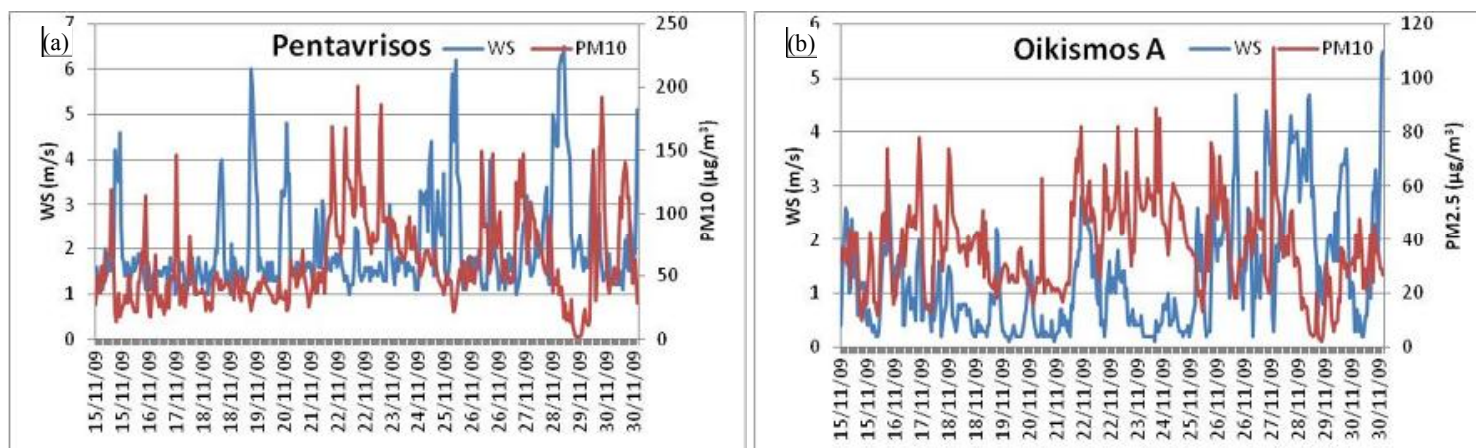

Figure 7. (a) Wind speed $\left(\mathrm{m} \mathrm{s}^{-1}\right)$ and PM10 $\left(\mu \mathrm{g} \mathrm{m}^{-3}\right)$ hourly values at Pentavrisos (Fig.1, measuring station 9) and, (b) Wind speed $\left(\mathrm{m} \mathrm{s}^{-1}\right)$ and PM2.5 $\left(\mathrm{\mu g} \mathrm{m}^{-3}\right)$ hourly values at Oikismos (Fig.1, measuring station 7 ) from $15^{\text {th }}$ to $30^{\text {th }}$ of November 

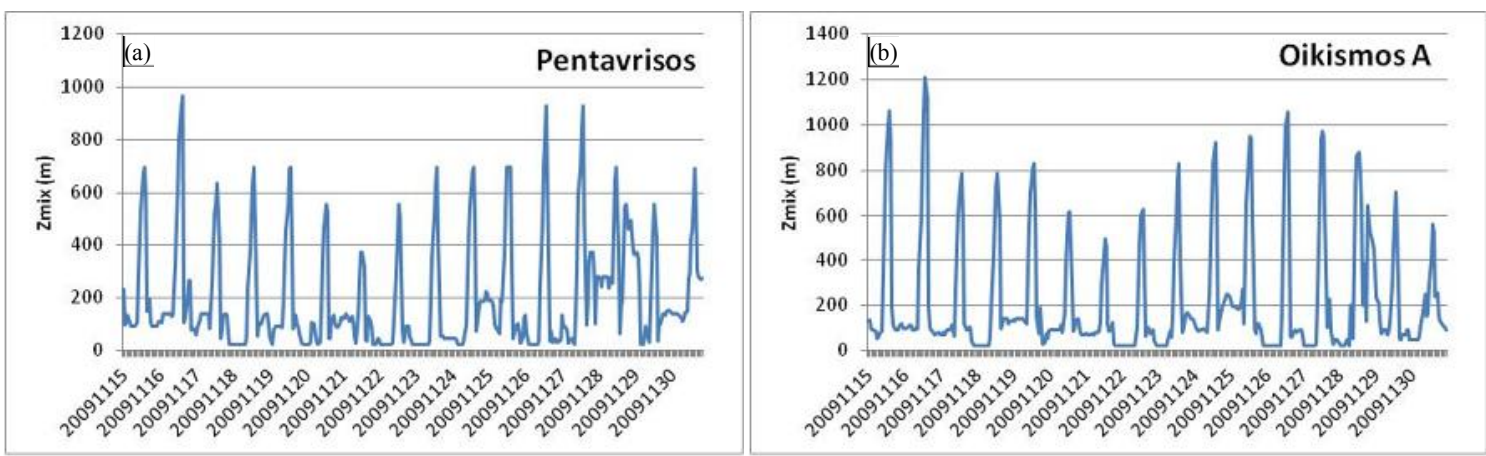

Figure 8. Mixing Height ( $\mathrm{m}$ ) hourly values at (a) Pentavrisos and (b) Oikismos A from $15^{\text {th }}$ to $30^{\text {th }}$ of November

The examination of the diurnal variation of the potential temperature vertical profiles produced by TAPM shows a strong surface temperature inversion existing during late afternoon, night and morning hours during most of the days of the episode. Figure 9 presents as examples the vertical profiles of potential temperature at Pentavrisos and Oikismos A stations, on the $21^{\text {st }}$ of November, just before the peak days of the episode. As can be seen, the base of the inversion is lifted only around the warm hours of the day and in some cases a shallow convective boundary layer is formed. In general, it was found that the diurnal variation of the bottom of the inversion follows a pattern similar to that of the mixing height. It becomes evident that pollutants are practically trapped in the lower boundary layer.
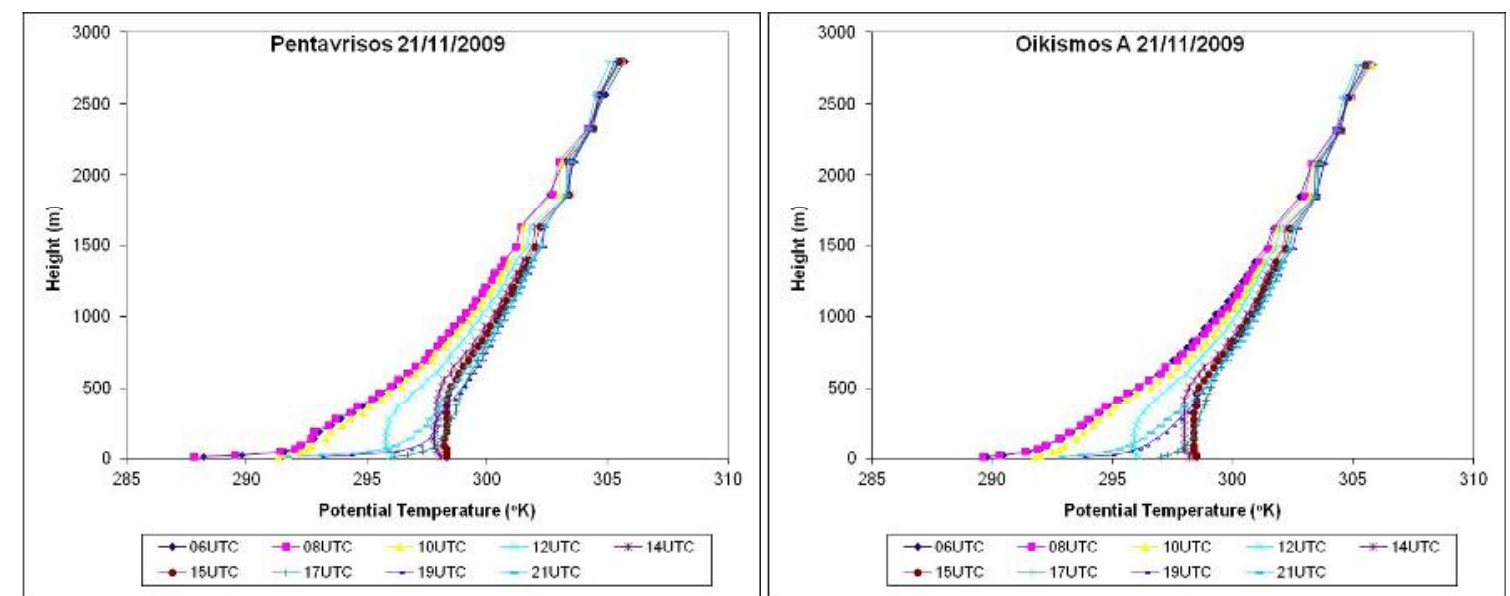

Figure 9. Vertical profiles of potential temperature at Pentavrisos and Oikimsos A

Finally, sounding data of the nearest station (Macedonia airport, Thessaloniki) were acquired from the University of Wyoming. Four of the most common and scientifically acknowledged indices (TTI, $\mathrm{LI}, \mathrm{SI}$ and $\mathrm{KI}$ ) were examined for the period from $14 / 11$ to $3 / 12$. Figure 10 presents the time evolution of these indices during this period. Relative stability is evident during the episode period, confirming the lack of significant synoptic forcing in the area. The only exception is an indication of week instability on the $24^{\text {th }}$ and $25^{\text {th }}$ expressed by the increased values of TTI. After the $29^{\text {th }}$ of November the instability increases significantly due to the passing of the second shortwave and the arrival of the depression at the first days of December. 


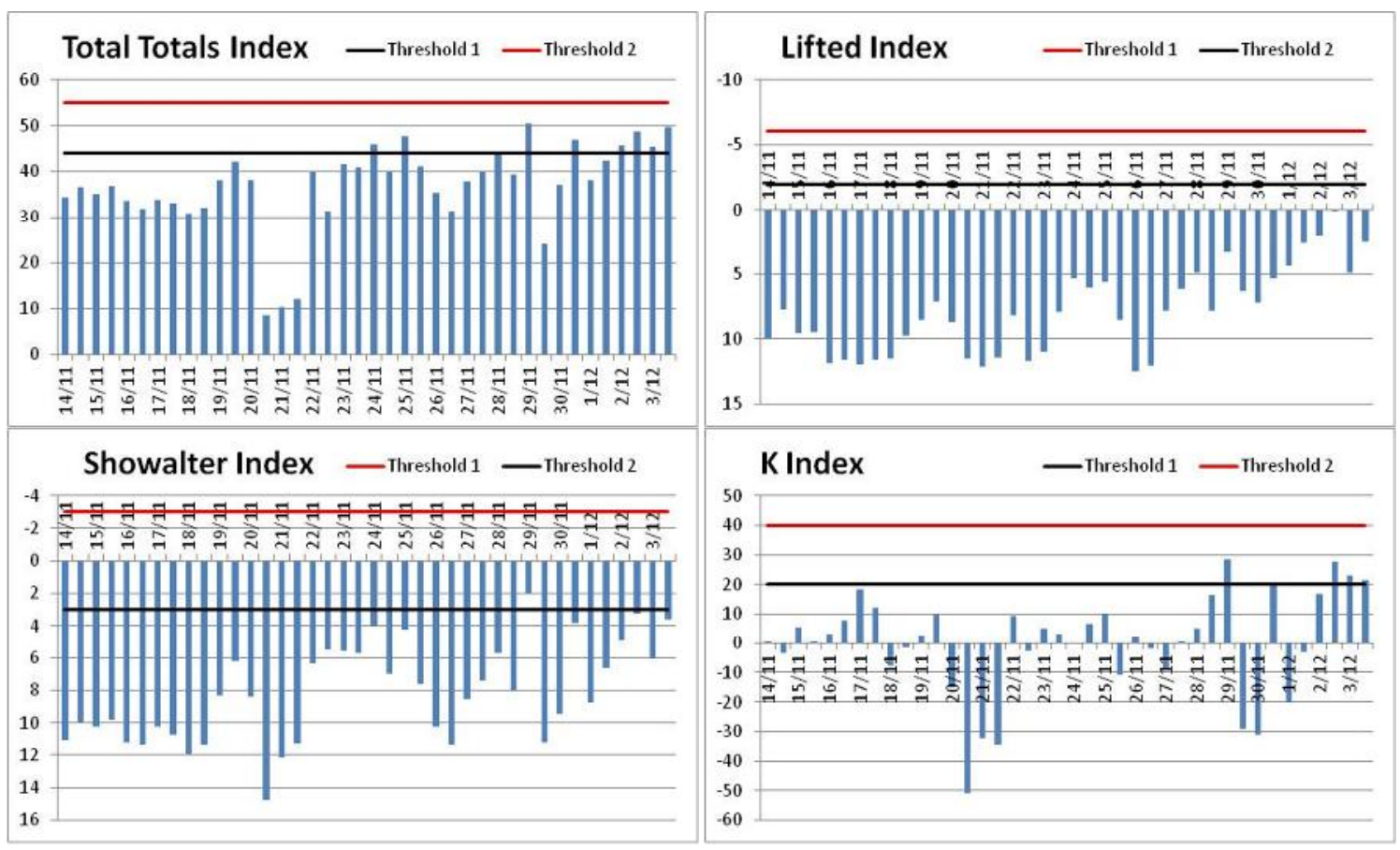

Figure 10. Time evolution of the four examined stability indices.

The black and red lines illustrate the threshold values of each index.

The vertical axis values are in reverse order for the two indices ( $\mathrm{LI}$ and $\mathrm{SI}$ )

where instability increases with the decrease of the index values

\section{CONCLUSIONS}

The evaluation and synthesis of the results presented in the previous section can be summarized in the following:

- The airborne particulate matter intensive pollution episode that was recorded in the BAPK during the last 15 days of November 2009 is the result of the synoptic setting that prevailed in the middle and lower troposphere. An Omega block followed by a high-over-low pattern in the southern Europe formed such a boundary layer structure in the area of interest, which favored high PM10 and PM2.5 concentrations.

- A ground based temperature inversion persisted during most of the days, except the warm hours of the day, when a shallow convective layer was developed. The lack of significant synoptic forcing allowed the lingering of the pollutants inside the boundary layer.

- The wind field in the surface and lower troposphere was very weak and assisted the trapping of pollutants in the lowest part of the boundary layer increasing the airborne particulate matter concentrations values.

- The PM10 and PM2.5 values are associated to the mixing height variation in the area, during the episode period.

- The change of the synoptic setting during the last days of the episode caused the development of significant synoptic forcing and the strengthening of the horizontal wind field near the surface, resulting in a significant decrease of PM10 and PM2.5 concentration. The rainfall that followed marked the end of the episode.

\section{ACKNOWLEDGMENTS}

The authors would like to thank the Greek Public Power Corporation for providing the data of its network in the BAPK. 


\section{REFERENCES}

Barmpadimos I., Hueglin C., Keller J., Henne S., and Prévôt A.S.H. (2011) Influence of meteorology on PM10 trends and variability in Switzerland from 1991 to 2008, Atmospheric Chemistry and Physics, $11,1813-1835$

Blanchard D.O. (1998) Assessing the Vertical Distribution of Convective Available Potetial Energy, Weather and Forecasting, 13, 870-877.

Derbyshire S.H. (1990) 'Nieuwstadt's stable boundary layer revisited', Quarterly Journal of the Royal Meteorological Society, 116, 127-158.

Elminir H.K. (2005) Dependence of urban air pollutants on meteorology, Science of the Total Environment, 350, 225-237.

Flocas H., Kelessis A., Helmis C., Petrakakis M., Zoumakis M., Pappas K. (2009) Synoptic and local scale atmospheric circulation associated with air pollution episodes in an urban Mediterranean area, Theoretical and Applied Climatology, 95, 265-277, doi:10.1007/s00704-008-0005-9.

Galway J.G. (1956) The lifted index as a predictor of latent instability, Bulletin of the American Meteorological Society, 37, 528-529.

George J.J. (1960) Weather forecasting for Aeronautics. Academic Press, New York, 409-415.

Hurley P. (1997) An evaluation of several turbulence schemes for the prediction of mean and turbulent fields in complex terrain, Boundary Layer Meteorology, 83, 43-73.

Hurley P., Blockley A., Rayner K. (2001) Verification of a prognostic meteorological and air pollution model for year-long predictions in the Kwinana region of Western Australia, Atmospheric Environment, 35,1871-1880, doi:10.1016/S1352-2310(00)00486-6.

Hurley P. (2002) The Air Pollution Model (TAPM) Version 2 Part1: technical description, CSIRO Atmospheric Research Technical Paper No.55.

Hurley P., Physick W., Luhar A. (2005) TAPM-A practical approach to prognostic meteorological and air pollution modeling, Environmental Modeling and Software, 20, 737-752, doi:10.1016/j.envsoft.2004.04.006.

Hurley P. (2008) The Air Pollution Model (TAPM) Version 4 Part1: technical description, CSIRO Atmospheric Research Technical Paper No.25.

Huschke R.E. (1959) Glossary of Meteorology, American Meteorological Society, Boston.

Kallos G., Kassomenos P., Pielke R.A. (1993) Synoptic and mesoscale weather conditions during air pollution episodes in Athens, Greece, Boundary Layer Meteorology, 62, 163-184. doi: 10.1007/BF00705553.

Karacostas Th., Kontogianni P., Roupa P., Lysitsa E., Brikas D., Mitas C. (2006) Study of the characteristics of omega blocking episodes over the major area of south-east Europe, Proceedings of the 8th Panhellenic Conference of Meteorology, Climatology and Atmospheric Physics, Athens, Greece, Hellenic Meteorological Society, 233-242.

Katzfey J.J. and Ryan B.F. (1997) Modification of the thermodynamic structure of the lower troposphere by the evaporation of precipitation: A GEWEX cloud system study, Monthly Weather Review, 125, $1431-1446$.

Larissi I.K., Antoniou A., Nastos P.T., Paliatsos A.G. (2010) The role of wind in the configuration of the ambient air quality in Athens, Greece, Fresenius Environmental Bulletin, 19, 1989-1996.

Miller R.C. (1967) Notes on analysis and severe storm forecasting procedures of the Military Weather Warning Center. AWS Technical Report 200 (revised).

McKendry I.G. (2000) PM10 Levels in the Lower Fraser Valley, British Columbia, Canada: An Overview of Spatiotemporal Variations and Meteorological Controls, Journal of the Air and Waste Management, 50:3, 443-452.

Proias G.T., Moustris K.P., Larissi I.K., Nastos P.T. Paliatsos A.G. (2012) Ambient PM10 concentrations and the impact of wind at an urban site in Central Greece. Fresenius Environmental Bulletin, 21, 1935-1941.

Rodríguez S., Querola X., Alastueya A., Mantilla E. (2002) Origin of high summer PM10 and TSP concentrations at rural sites in Eastern Spain, Atmospheric Environment, 36, 3101-3112.

Showalter A.K. (1953) A stability index for thunderstorm forecasting, Bulletin of the American Meteorological Society, 34, 250-252.

Triantafyllou A.G. (2001) PM10 pollution episodes as a function of synoptic climatology in a mountainous industrial area, Environmental Pollution, 112/3, 91-500, doi:10.1016/S0269-7491(00)00131-7.

Triantafyllou A.G. (2003) Levels and trend of suspended particles around large lignite power stations, Environmental Monitoring and Assessment, 89, 15-34. doi: 10.1023/A:1025829907390. 
Triantafyllou A.G., Krestou A., Hurley P. and Thatcher M. (2011) An operational high resolution localscale meteorological and air quality forecasting system for Western Macedonia, Greece: Some first results, Proceedings of the 12th International Conference on Environmental Science \& Technology (CEST2011), 8 - 10 September 2011, A, 1904-1911.

Wyoming Weather Web, URL:http://weather.uwyo.edu/, last accessed on November 1, 2012.

Zoras S., Triantafyllou A.G, Hurley P.J. (2007) Grid sensitivity analysis for the calibration of a prognostic meteorological model in complex terrain by a screening experiment, Environmental Modeling and Software, 22, 33-39. 